\title{
Prevalence, associated risk factors and antimicrobial susceptibility patterns of Shigella infections among diarrheic pediatric population attending at Gondar town healthcare institutions, Northwest Ethiopia
}

\author{
Amare Alemu' ${ }^{1}$, Mekuanint Geta', Selomon Taye ${ }^{2}$, Setegn Eshetie ${ }^{1}$ and Tigist Engda ${ }^{1 *}$
}

\begin{abstract}
Background: Diarrhea caused by Shigella species remains a major public health threat especially in the pediatric population. A regular surveillance system needs to be in place, in order to explore the burden, antimicrobial resistance patterns and associated risk factors for Shigella infections. Therefore, the aim of this study was to assess the prevalence, antimicrobial susceptibility patterns and associated risk factors of Shigella infections among diarrheic pediatric population attending at selected healthcare institutions in Gondar town.

Methods: A cross-sectional study was conducted in Gondar town healthcare institutions from January to March 2018. A simple random sampling technique was used to enroll 272 study participants. Structured questionnaires were used to gather socio-demographic, environmental and associated risk factors data. Stool samples were collected from diarrheic pediatric patients and inoculated onto MacConkey media, salmonella-shigella agar, and xylose-lysine deoxy-cholate agar. Identification of the bacterial species was carried out by using biochemical tests. The disc-diffusion method was used to determine the antimicrobial susceptibility of the isolates by standardizing the bacterial suspension with a 0.5 McFarland solution. A statistical analysis was done using SPSS version 20 statistical package and $P$-value $<0.05$ was considered as statistically significant.

Results: From the total study participants, 29(10.7\%) of the patients were culture positive for Shigella species. The habit of eating raw food and nutritional status of children were statistically significant with shigellosis $(p<0.05)$. Shigella species were found highly resistant to amoxicillin and tetracycline but susceptible to nitrofurantoin and norfloxacin.

Conclusion: High prevalence of Shigella species were detected in this study. Through in-vitro drug susceptibility testing, norfloxacin and nitrofurantoin were found to be effective against the isolates, while high resistance rates were observed for tetracycline, and amoxicillin. The findings highlighted the need for regular drug resistance information for the best management of infections.
\end{abstract}

Keywords: Shigella, Prevalence, Risk factors, Pediatric population, Antibiotic resistance, Diarrhea

\footnotetext{
* Correspondence: tigiengda@gmail.com

${ }^{1}$ Department of Medical Microbiology, School of Biomedical and Laboratory Sciences, College of Medicine and Health Sciences, University of Gondar, 196 Gondar, Ethiopia

Full list of author information is available at the end of the article
}

(c) The Author(s). 2019 Open Access This article is distributed under the terms of the Creative Commons Attribution 4.0 International License (http://creativecommons.org/licenses/by/4.0/), which permits unrestricted use, distribution, and reproduction in any medium, provided you give appropriate credit to the original author(s) and the source, provide a link to the Creative Commons license, and indicate if changes were made. The Creative Commons Public Domain Dedication waiver (http://creativecommons.org/publicdomain/zero/1.0/) applies to the data made available in this article, unless otherwise stated. 


\section{Background}

Diarrheal diseases remain one of the most dominant public health problems in these days. Gastrointestinal infections due to Shigella species are important cause of mortality and morbidity worldwide; primarily children under the age of 5 years are at high risk. Shigella species are members of Enterobacteriaceae characterized by non-lactose fermenters, gram-negative rods, facultative anaerobes, non-motile, and non-gas producer [1, 2].

To initiate infection 100 ingested Shigella microorganisms are enough to cause acute diarrhea after 4-7 days [2, 3]. After Shigella enter the human body they remain in the cytoplasm of the epithelial cells and spread laterally to invade adjacent cells which result in the formation of abscesses and ulcerations with a high concentration of neutrophils in the stool [1]. Shigella species have a lot of virulence factors that allow it to adhere to the epithelium of the intestine, survive stomach acid, invade host cells, evade immune responses, and introduce toxins into the body. Invasion of plasmid antigen $\mathrm{B}(\mathrm{IpaB})$ enables it to attach to the host cell and facilitates pathways that destroy macrophages when infection is initiated. Invasion plasmid antigen $\mathrm{C}(\mathrm{IpaC})$ triggers proteins to form the actin-polymerizing compound that allows Shigella to pass and spread within host cells [1, 4].

Shigella species cause mild to severe forms of gastrointestinal tract infections that are limited to the intestinal tract of humans and cause bacillary dysentery which is characterized by watery or bloody diarrhea [1, 3]. Shigellosis is still accounts for a significant proportion of morbidity and mortality especially; in children with diarrhea in developing countries. Globally; Shigellosis causes an approximately of 165 million cases of severe diarrhea [1]. In developing world; More than one million death occur yearly due to infections by Shigella species however in Africa, an estimate of 115 people dies of diarrheal diseases every hour is mostly due to shigellosis $[3,5,6]$.

Global incidences of Shigella species are related to many factors comprising of raw meat consumption, extensive field slaughtering practices, unhygienic food handling practices and unsafe water supply [7, 8]. Shigella species can be disseminated from person to person feco-orally. Culture, biochemical tests and routine microscopy must be carried out to diagnose shigellosis. For molecular techniques, the most common methods used in the developed world are the pulsed-field gel electrophoresis (PFGE) and multiple loci sequence typing (MLST) [1-3].

Antibiotic resistance has become a major concern to control diarrhea in children. Increasing antimicrobial resistance has complicated for the selection of antibiotics in treating shigellosis. Over the past decades Shigella species showed a persistent increase in antimicrobial resistance to routinely prescribed antimicrobials. In Ethiopia, Shigella have been reported to be resistant to first-line antibiotics such as ampicillin, tetracycline, and amoxicillin [9-11]. Therefore, identification of the prevalence, associated risk factors and resistance patterns of Shigella species in diarrheal pediatric population is compulsory.

\section{Methods}

\section{Study area, design and period}

Institution based cross-sectional study was conducted at the selected health institution in Gondar town from January 2018 to March 2018. The town is $747 \mathrm{~km}$ northwest to Addis Ababa, the capital city of Ethiopia. Based on Federal Democratic Republic of Ethiopia Central Statistical Agency (CSA), population projection of Ethiopia from 2014 to 2017, the town has an estimate of 341,991 populations [12]. One comprehensive specialize referral hospital and 8 health centers and one private specialized pediatric clinic are currently giving health service to the community. Among these, one comprehensive specialized hospital, two health centers and one specialized pediatric clinic are selected for the study.

\section{Population}

The Source population was all pediatric population under 14 years of age and lives in Gondar town during the study period. And the study population was all diarrheic pediatric populations in the selected health institutions seeking medical service during the study period.

\section{Sample size determination and sampling techniques}

The sample size was calculated using a single population proportion formula based on the assumption of $5 \%$ expected margins of error, considering 95\% confidence interval, $10 \%$ non-response rate and by taking the prevalence of $20.1 \%$ from the previous study [13]. The final sample size became 272 .

Simple random sampling method was employed to select study sites and their sample size was allocated proportionally. Accordingly; 119, 25, 30 and 98 study subjects were enrolled in Gondar university compressive specialized hospital, Maraki health center, Gondar health center and Dr. Mihretie specialized pediatric clinic respectively.

\section{Data collection and laboratory processing}

A structured questionnaire was administered to the child's parent or guardian to collect data on basic socio-demographic character and potential risk factors for infection. A clean stool cups were given to parents or guardians with proper instruction on specimen collection. Each specimen was checked for its 
labeling, quantity and procedure of collection. Then the specimens were transported with selenite F broth transport media to University of Gondar medical microbiology laboratory.

\section{Culture and identification}

The collected samples were immediately processed for bacteriological analysis. A loop full stool sample suspension was inoculated onto MacConkey and incubated at 37 ${ }^{\circ} \mathrm{C}$ for $24 \mathrm{~h}$. Pure non-lactose fermenter colony was transferred to salmonella-shigella agar (SS agar) and xyloselysine-deoxycholate agar (XLD) and incubated at $37^{\circ} \mathrm{C}$ for further $24 \mathrm{~h}$. Colorless colonies from MacConkey agar, red-pink colonies from xylose-lysine-deoxycholate agar, and colorless colonies mostly with black centers due to $\mathrm{H}_{2} \mathrm{~S}$ production on SS agar were considered non-lactose fermenting colonies. Culture-negative specimens on SS agar and XLD agar media were sub-cultured in Selenite F broth to improve the recovery of the isolates and were identified by repeated sub-culturing before discarded. Typical non-lactose fermenter colonies were subjected to standard biochemical tests to identify Shigella species. Biochemical tests were also carried out by inoculation of Klingler iron agar, Simon's citrate agar, lysine iron agar, and MIU test (motility test, Indole and Urease production) for final identification.

\section{Antimicrobial susceptibility testing}

Suspension of Shigella species were prepared by taking pure colonies from isolates with a sterile wire loop and suspended in sterile nutrient broth and then incubated for $2 \mathrm{~h}$ [14]. The turbidity of the suspensions to be inoculated were equilibrated to match with $0.5 \mathrm{McFarland}$ standards. A sterile cotton swab was used and additional suspensions were removed by gentle rotation of the swab against the surface of the tube and then spread consistently over the Muller Hinton agar plate. The selected antimicrobials were dispensed using sterile forceps on the medium and incubated at $37^{\circ} \mathrm{C}$ for $24 \mathrm{~h}$. Then the diameter of zone of inhibition around the disc was measured to the nearest millimeter using a caliper and the isolates were classified as sensitive, intermediate, and resistant as recommended by "(CLSI 2017)". Each isolate was tested for amoxicillin $(10 \mu \mathrm{g})$, tetracycline $(30 \mu \mathrm{g})$, cotrimoxazole $(25 \mu \mathrm{g})$, chloramphenicol $(10 \mu \mathrm{g})$, norfloxacin $(5 \mu \mathrm{g})$, nitrofurantoin $(30 \mu \mathrm{g})$, azithromycin $(15 \mu \mathrm{g})$, and amoxicillin-clavulanate $(10 \mu \mathrm{g})$ and interpreted as sensitive; intermediate and resistant following the method of CLSI 2017 [15].

\section{Data management and quality assurance}

To generate quality and reliable data; all questions were prepared in a clear and precise way and translated into local language (Amharic). Data collectors were trained and the entire questionnaire was checked for completeness, during and after data collection by the data collectors. The raw data were checked for completeness and representativeness before entry into database. Moreover, all laboratory procedures were done by maintaining quality control procedures by following standard operating procedures (SOPs) in the detection and identification of Shigella in stool samples. The culture media were checked for sterility by incubating representative of the batch at $37^{\circ} \mathrm{C}$ overnight and observing the growth of organism. Those batches of the media that showed growth were discarded. Control strains of Escherichia coli ATCC 25922, Salmonella Typhi ATCC 13311, Salmonella enteritis's ATCC 13076, Salmonella Sonni ATCC 25331 were used for culture and sensitivity testing [16].

\section{Data analysis}

After the completion of data collection, the questionnaire was checked for its completeness, unrecorded values and unlikely responses and then cleaned up manually on such indication. The laboratory analysis result was registered on the laboratory data collection format sheet. From data collection format sheet, pre-coded and checked data was entered to Epi data version 3.1 and then exported to SPSS version 20 for statistical analysis. The base line characteristics of the study population were summarized using descriptive statistics. Internal comparison was made using logistic regression to determine the effect of independent variables by calculating the strength of association between infection and associated factors using odds ratio (OR) and taking 95\% confidence interval (CI). Odds Ratio was computed using binary logistic regression analysis. Adjusted OR with 95\% CI were used to assess the strength of association and $P$-value $<0.05$ were used to assess statistical significance.

\section{Ethical consideration}

This study was ethically approved by Ethical Review Committee of University of Gondar, College of Medicine and Health Sciences, school of Biomedical and Laboratory Sciences. Permission was sought from each health institution. Written assent was taken from each children's parent/guardian after they understood the purpose of the study. All the subjects' data were kept in full confidentiality and was not be disclosed to an unauthorized person.

\section{Results}

Socio-demographic characteristics

A total of 272 diarrheic pediatric patients of age $\leq 14$ years were included in the study. Of these, 15(55.5\%) were males and $12(44.5 \%)$ were females. The mean age 
of the participants was 4.6 years. The majority, 18(66.5\%) of the study participants were under 5 years. Most of the participants, 25(92.3\%) were from the urban residence and $80(29.4 \%)$ of the parents completed at least college diploma (Table 1).

\section{Prevalence of Shigella species}

Of the total 272 study participants, 29(10.7\%) were positive for Shigella species. The highest prevalence 22(12.2\%) of Shigella species were found in under five years children. Seven (7.7\%) Shigella species were observed in the age group above five years (Table 2).

The distribution of Shigella species in Gondar University specialized Hospital, Gondar Health center, Maraki Health center and Dr. Mihretie Specialty Pediatric private clinic were $7(5.9 \%), 5(16.7 \%), 6(24.0 \%)$ and $11(11.2 \%)$ respectively (Table 3).

\section{Antimicrobial susceptibility patterns of shigella species} In this study from the isolated Shigella species 93.1 and $89.7 \%$ were resistant to amoxicillin and tetracycline respectively however 75.9 and $93.1 \%$ were susceptible to norfloxacin and nitrofurantoin respectively (Table 4). Moreover; 22(76\%) Shigella isolates were found to be resistant to a combination of three or more routinely prescribed drugs (Table 5).

\section{Associated risk factors of Shigella species infections}

Associated risk factors to Shigella species infections were analyzed by using binary logistic regression. Many variables were tend to be more associated with developing an infection but did not reach statistical

Table 1 Distributions of socio-demographic characteristics of children and parents attended at selected Gondar town healthcare institutions, Northwest Ethiopia, 2018, $n=272$

\begin{tabular}{llll}
\hline Variables & Categories & Frequency & Percent(\%) \\
\hline Sex & Male & 151 & 55.5 \\
\multirow{3}{*}{ Age } & Female & 121 & 44.5 \\
\multirow{2}{*}{ Residence } & $\leq 5$ & 181 & 66.5 \\
& $>5$ years & 91 & 33.5 \\
Income (family) & Urban & 251 & 92.3 \\
& Rural & 21 & 7.7 \\
& 500-1000 birr & 19 & 7 \\
Educational status & 69 & 25.4 \\
& > Illiterate & 184 & 67.6 \\
& Only read and write & 32 & 21.7 \\
& Primary school & 54 & 11.8 \\
& Secondary school & 47 & 17.3 \\
& College and university & 80 & 29.4 \\
\hline
\end{tabular}

significance. Multivariable logistic regression showed that raw food consumption, malnutritional status of the children and literacy of parents had a statistically significant association with the prevalence of Shigella species infections in the pediatric population. Illiterate mothers' children were $3.5(P=0.047$; AOR $=3.49$; $\mathrm{CI}$ $=1.01-12.04)$ times more likely to be infected with Shigella. The prevalence of shigellosis was lower among children whose mothers had secondary and above educational statuses.

The study also showed that there is a statistical association between Shigella infection and the consumption of raw foodstuffs. Children who had consumed raw food were $3.7(P=0.006 ; \mathrm{AOR}=3.66 ; \mathrm{CI}=1.45-9.24)$ times more likely to have Shigella infection. Moreover; malnourished children were to be greatly infected with Shigella species (Table 2).

\section{Discussion}

Intestinal infections due to pathogenic Enterobacteriaceae especially Shigella species are important causes of morbidity and mortality globally $[1,2]$. In this study the total prevalence of Shigella species were 29(10.7\%) $(95 \% \mathrm{CI}=7.0-14.0 \%)$ in all age groups and was in consistent with studies carried out in Bahir Dar, Ethiopia 8.4\% [10], Sydney, Australia 8.9\% [17] and Brazil 10\% [16]. However; it was lower than studies from Unguja Island-Zanzibar 38.5\% [5], India 39.6\% [18], Nepal 52.2\% [19], Saudi Arabia 61.3\% [20], Lebanon 30\% [21], Iran $40 \%$ [22]. The reason is that the investigators might use advanced techniques for the detection of Shigella species. In contrast the result was higher than studies carried out from Hawassa, south Ethiopia 3.6\% [23], Jimma, southwest Ethiopia 1.1\% [9], Ankara, Turkey 3.2\% [24], China 3.6\% [25], Windhoek, Namibia 1.3\% [26]. This might be due to associated risk factors exposed to Shigella species differ in different place and countries; as a result, the prevalence of shigellosis would be different in time and place.

The highest prevalence of 22(12.2\%; 95\% CI $=7.2$ 17.1\%) Shigella species in this study were observed in children aged under five years. This result is in agreement with a study carried out in Addis Ababa, Ethiopia (9.1\%) [27], Mekelle, northern Ethiopia (13.3\%) [28], Windhoek, Namibia, (13.3\%) [26], and Sydney, Australia (11.1\%) [17]. The main reasons are younger children are exposed to many environmental factors such as playing with contaminated soil, eating contaminated food and drinking contaminated water than an elder child. Furthermore; small children are immunologically naive and delay in humoral immunity response resulted to more susceptible to infection and also they can produce little hydrochloric acid (gastric $\mathrm{HCl}$ ) which is a natural barrier to many microorganisms [1, 
Table 2 Prevalence and associated risk factors of Shigella species in diarrheic pediatric population attended at selected Gondar town healthcare institutions, Northwest Ethiopia, 2018, n=272

\begin{tabular}{|c|c|c|c|c|c|c|}
\hline \multirow[t]{2}{*}{ Variables } & \multirow[t]{2}{*}{ Categories } & \multicolumn{5}{|c|}{ Results of Shigella species } \\
\hline & & Positive (\%) & Negative (\%) & COR(95\%Cl) & AOR $(95 \% \mathrm{Cl})$ & P-value \\
\hline \multirow[t]{2}{*}{ Sex } & Male & $18(11.9 \%)$ & 133(88.1\%) & $1.35(0.61-2.98)$ & - & \\
\hline & Female & $11(9.1 \%)$ & $110(90.9 \%)$ & 1 & - & \\
\hline \multirow[t]{2}{*}{ Age } & $\leq 5$ years & $22(12.2 \%)$ & 159(87.8\%) & $1.66(0.68-4.04)$ & - & \\
\hline & $>5$ years & $7(7.7 \%)$ & 84(92.3\%) & 1 & - & \\
\hline \multirow[t]{2}{*}{ Breast feeding } & Yes & $14(12.4 \%)$ & $99(87.6 \%)$ & 1 & - & \\
\hline & No & $15(9.4 \%)$ & 144(90.6\%) & $0.74(0.3401 .59)$ & - & \\
\hline \multirow[t]{2}{*}{ Residence } & Urban & $25(10.0 \%)$ & $226(90.0 \%)$ & 1 & - & \\
\hline & Rural & $4(19.0 \%)$ & $17(81.0 \%)$ & $2.13(0.66-6.82)$ & $1.43(0.35-5.89)$ & 0.622 \\
\hline \multirow[t]{3}{*}{ Income (family) } & $<500$ & $4(19.0 \%)$ & $17(81.0 \%)$ & $2.80(0.83-9.45)$ & $2.69(0.62-11.63)$ & 0.186 \\
\hline & $500-1000$ & $9(13.4 \%)$ & $58(86.6 \%)$ & $1.56(0.66-3.75)$ & - & \\
\hline & $>1000$ & $16(8.7 \%)$ & 168(91.3\%) & 1 & - & \\
\hline \multirow[t]{5}{*}{ Educational (family) } & Illiterate & $15(25.4 \%)$ & $44(74.6 \%)$ & $5.11(1.74-15.03)$ & $3.49(1.01-12.04)$ & 0.047 \\
\hline & Only read and write & $1(3.1 \%)$ & $31(96.9 \%)$ & $0.48(0.05-4.31)$ & - & \\
\hline & Primary school & $6(11.1 \%)$ & 48(88.9\%) & $1.87(0.54-6.48)$ & - & \\
\hline & Secondary school & $2(4.3 \%)$ & 45(95.7\%) & $0.67(0.12-3.58)$ & - & \\
\hline & College and university & $5(6.2 \%)$ & 75(93.8\%) & 1 & 1 & \\
\hline \multirow[t]{3}{*}{ Water source } & Unprotected well water & $2(18.2 \%)$ & $9(81.8 \%)$ & $1.94(0.40-9.47)$ & - & \\
\hline & Surface water & $2(11.1 \%)$ & 16(88.9\%) & $1.09(0.24-5.02)$ & - & \\
\hline & Piped tap water & $25(10.3 \%)$ & 218(89.7\%) & 1 & - & \\
\hline \multirow[t]{2}{*}{ Domestic animals } & Yes & $8(14.3 \%)$ & $48(85.7 \%)$ & $1.55(0.65-3.71)$ & - & \\
\hline & No & $21(9.7 \%)$ & 195 (90.3\%) & 1 & - & \\
\hline \multirow[t]{2}{*}{ Raw food } & Yes & $21(18.4 \%)$ & $93(81.6 \%)$ & $4.23(1.80-9.95)$ & $3.66(1.45-9.24)$ & 0.006 \\
\hline & No & $8(5.1 \%)$ & 150(94.9\%) & 1 & 1 & \\
\hline \multirow[t]{2}{*}{ Toilet } & Open defecation & 14 (20.9\%) & $53(79.1 \%)$ & $3.35(1.52-7.37)$ & $1.88(0.73-4.84)$ & 0.192 \\
\hline & Latrine usage & $15(7.3 \%)$ & 190 (92.7\%) & 1 & - & \\
\hline \multirow[t]{4}{*}{ Hand Washing } & Before preparing food & $13(12.3 \%)$ & $93(87.7 \%)$ & $1.94(0.66-5.68)$ & $1.45(0.44-4.73)$ & 0.541 \\
\hline & After defecating child & $6(12.2 \%)$ & $43(87.8 \%)$ & $1.95(0.56-6.79)$ & $1.50(0.36-6.19)$ & 0.579 \\
\hline & After toilet use & $5(11.9 \%)$ & $37(88.1 \%)$ & $1.94(0.53-7.16)$ & - & \\
\hline & After cleaning anything & $5(6.7 \%)$ & $70(93.3 \%)$ & 1 & - & \\
\hline \multirow[t]{2}{*}{ Nutritional status } & Normal & $24(9.3 \%)$ & 235 (90.7\%) & 1 & 1 & \\
\hline & Malnourished & $5(38.5 \%)$ & 8 (61.5\%) & $6.12(1.85-20.19)$ & $5.56(1.42-21.76)$ & 0.014 \\
\hline
\end{tabular}

COR Crude Odds Ratio, AOR Adjusted Odds Ratio

Table 3 The distribution of Shigella species in relation to different study sites in diarrheic pediatric population attended at selected Gondar town healthcare institutions, Northwest Ethiopia, 2018, $n=272$

\begin{tabular}{llclll}
\hline $\begin{array}{l}\text { Bacterial } \\
\text { Species }\end{array}$ & Results & Hospital and Health Centers & & \\
\cline { 3 - 6 } & & GUCRH $(n=119)$ & $\begin{array}{l}\text { Gondar Health } \\
\text { Center }(n=30)\end{array}$ & $\begin{array}{l}\text { Maraki Health } \\
\text { Center }(n=25)\end{array}$ & $\begin{array}{l}\text { Dr. Mihretie Pediatric } \\
\text { Specialty Clinic } \\
(n=98)\end{array}$ \\
\hline Shigella species & Positive $n(\%)$ & $7(5.9 \%)$ & $5(16.7 \%)$ & $6(24.0 \%)$ & $11(11.2 \%)$ \\
& Negative $n(\%)$ & $112(94.1 \%)$ & $25(83.3 \%)$ & $19(76.0 \%)$ & $87(88.8 \%)$ \\
\hline
\end{tabular}


Table 4 Antimicrobial susceptibility patterns of Shigella isolates among diarrheic pediatric population attended at selected Gondar town Healthcare institutions, Northwest Ethiopia, 2018

\begin{tabular}{llll}
\hline Antibiotic Disc & \multicolumn{3}{l}{ Shigella species $(n=29)$} \\
\cline { 2 - 4 } & $\mathrm{S}(\%)$ & $\mathrm{I}(\%)$ & $\mathrm{R}(\%)$ \\
\hline Amoxicillin (AMX) & $1(3.4 \%)$ & $1(3.4 \%)$ & $27(93.1 \%)$ \\
Norfloxacin (NOR) & $22(75.9 \%)$ & $5(17.2 \%)$ & $2(6.9 \%)$ \\
Cotrimoxazole (SXT) & $5(17.2 \%)$ & $12(41.4 \%)$ & $12(41.4 \%)$ \\
Amoxicillin-clavulanate (AMC) & $14(48.3 \%)$ & $12(41.4 \%)$ & $3(10.3 \%)$ \\
Chloramphenicol (CAF) & $5(17.2 \%)$ & $11(37.9 \%)$ & $13(44.8 \%)$ \\
Tetracycline (TE) & $2(6.9 \%)$ & $1(3.4 \%)$ & $26(89.7 \%)$ \\
Nitrofurantoin (NIT) & $27(93.1 \%)$ & $2(6.9 \%)$ & $0(0.0 \%)$ \\
Azithromycin (AZM) & $13(44.8 \%)$ & $6(20.7 \%)$ & $10(34.5 \%)$
\end{tabular}

$S$ Susceptible, I Intermediate, $R$ Resistance

16, 29]. Seven $(7.7 \%)(95 \% \mathrm{CI}=3.3-13.2 \%)$ of Shigella species were isolated in children aged above five years which was in agreement with studies done in Bahir Dar, northwest Ethiopia (3.3\%) [10] and Sydney, Australia (6.7\%) [17].

Table 5 Multi-Drug Resistance patterns (MDR) of Shigella species isolated from diarrheic pediatric population attended at selected Gondar town Healthcare institutions, Northwest Ethiopia, 2018, $n=272$

\begin{tabular}{|c|c|c|c|}
\hline Species & Resistance Antibiotics & Number of organisms & group \\
\hline \multirow[t]{5}{*}{ Shigella $(n=5)$} & AMX & 1 & R1 \\
\hline & CAF & 1 & \\
\hline & TE & & \\
\hline & AZM & 1 & \\
\hline & AMC & & \\
\hline \multirow[t]{6}{*}{ Shigella $(n=6)$} & SXT, AMX & 1 & R2 \\
\hline & AMC, CAF & 1 & \\
\hline & TE, AZM & 1 & \\
\hline & AZM, NIT & 1 & \\
\hline & TE, CAF & 1 & \\
\hline & NOR, AMX & 1 & \\
\hline \multirow[t]{11}{*}{ Shigella $(n=11)$} & AMX, TE, CAF, AZM & 1 & R3 \\
\hline & TE, AMC, AZM & 1 & \\
\hline & TE, CAF, AZM & 1 & \\
\hline & $A M X, S X T, A M C, C A F$ & 1 & \\
\hline & TE, AZM, SXT & 1 & \\
\hline & AMX, SXT, CAF & 1 & \\
\hline & AMX, SXT, AMC & 1 & \\
\hline & TE, AZM, SXT & 1 & \\
\hline & AMX, TE, AZM, SXT & 1 & \\
\hline & TE, AMC, SXT & 1 & \\
\hline & AMX, SXT, CAF, TE & 1 & \\
\hline
\end{tabular}

$R 1$ Resistance for one drug, $R 2$ Resistance for two drugs, $\geq \mathrm{R} 3$ Resistance for three or more drug
Multivariable logistic regression showed that raw food consumption, nutritional status of the children and illiteracy of parents has a statistically associated with the prevalence of Shigella species infections in pediatric population. In this study, malnourished children were $5.6(P=0.014)$ times more likely to be infected with Shigella species. This is due to the fact that malnourished children are unable to produce protective immune system which leads to varies enteric disease including shigellosis. Raw food consumption also $3.7(P=0.006)$ times more likely to develop Shigella infection as compared with those who did not eat raw food. This might be due to raw foodstuffs were contaminated with waste products of an infected individuals and consumption of water and food from unprotected sources. Moreover, illiterate mothers (parents) were $3.5(P=0.047)$ times more likely to expose their children for Shigella species infection than any other educated mothers or parents. This might be due to lack of knowledge on risk factors which exposed children to diarrheal diseases.

Shigella isolates in this study were susceptible to norfloxacin (75.9\%) and nitrofurantoin (93.1\%). This was in line with a study done in Bahir Dar town, Ethiopia nitrofurantoin (93.9\%) [30] and Kathmandu, Nepal, norfloxacin (91.7\%) [19]. However, Shigella species in this study were resistant to amoxicillin (93.1\%) and tetracycline (89.7\%) which was comparable with studies conducted in Harar, Eastern Ethiopia, tetracycline (96.4\%) [11], Harar, Eastern Ethiopia, tetracycline (70.6\%) [31], China, amoxicillin (93.2\%) and tetracycline (90.9\%) [32]. Twenty-two (76\%) Shigella species in this study were resistant to three or more routinely prescribed drugs. The high percentage of resistant isolates to amoxicillin, tetracycline and other drugs might be either they were regularly and unnecessarily prescribed or people can have easily access to these drugs from community pharmacy without prescription [14]. Drug resistance varies in different areas might be due to the difference in strains of Shigella species.

\section{Conclusions}

High prevalence of Shigella species infections were demonstrated in this study, dominantly in children under five years. Besides the associated risk factors such as the habit of eating raw food and the nutritional status of the child predisposes them to Shigella species infections. In addition, high drug resistance in Shigella species was observed especially for amoxicillin and tetracycline. This study also revealed that norfloxacin and nitrofurantoin can be used as the drug of choice for shigellosis. Health policy makers and stakeholders must be vigilant to prevent these nasty diseases in pediatric population. The limitation of this 
study was identification of Serogroup of Shigella species was not performed due to financial constraints and lack of advanced technology in the existed facilities. Therefore; regular surveillance on the prevalence, antimicrobial susceptibility and identification of serogroups and serotypes of Shigella isolates need to be evaluated.

\section{Abbreviations}

AOR: Adjusted Odds Ratio; ATCC: American Type Culture Collection Cl: Confidence Interval; CLSI: Clinical Laboratory Standards Institute; COR: Crude Odds Ratio; GUCSH: Gondar University Comprehensive Specialized Hospital; MDR: Multi-Drug Resistance; MUAC: Middle Upper Arm Circumference; QC: Quality Control; SPSS: Statistical Package for Social Sciences; SS Agar: Salmonella-Shigella Agar; USA: United States of America; WHO: World Health Organization; XLD: Xylose-Lysine-Deoxycholate Agar

\section{Acknowledgments}

We are grateful to thank the Department of Medical Microbiology, School of Biomedical and Laboratory Sciences, College of Medicine and Health Sciences, University of Gondar for their technical and financial support. We would like to extend our great full to all staffs of Medical Microbiology department who have been involved directly or indirectly in this study. Yet importantly we would like to express our deepest gratitude and especial respect to study participants for their voluntary participants in this study.

\section{Funding}

This study was funded by University of Gondar. The funds were used in the data collection, analysis, and report writing only.

\section{Availability of data and materials}

The original data for this study is available from the corresponding author.

\section{Authors' contributions}

AA: Primary researcher conceived the idea for this study. MG, ST, SE and TE: participated in data collection, conducted data analysis, drafted and finalized the manuscript for publication. All authors read and approved the final manuscript.

\section{Ethics approval and consent to participate}

This study was ethically approved by Ethical Review Committee of University of Gondar, College of Medicine and Health Sciences, school of Biomedical and Laboratory sciences. Permission was obtained from each health institution. Written assent was taken from each child's parent/guardian after they understood the purpose of the study. All the subjects' data were kept in full confidentiality and was not be disclosed to an unauthorized person.

\section{Consent for publication}

Not applicable.

\section{Competing interests}

The authors declare that they have no competing interests.

\section{Publisher's Note}

Springer Nature remains neutral with regard to jurisdictional claims in published maps and institutional affiliations.

\section{Author details}

'Department of Medical Microbiology, School of Biomedical and Laboratory Sciences, College of Medicine and Health Sciences, University of Gondar, 196 Gondar, Ethiopia. ${ }^{2}$ Department of Medical Microbiology, College of Health Sciences, Wachamo University, Wachamo, Southern Ethiopia.

Received: 30 October 2018 Accepted: 21 March 2019

Published online: 18 April 2019

\section{References}

1. Greenwood D, Slack RC, Barer MR, Irving WL. Medical microbiology E-book: a guide to microbial infections: pathogenesis, immunity, laboratory diagnosis and control. With STUDENT CONSULT Online Access: Elsevier Health Sciences. 2012.

2. Gladwin M, Trattler B. Clinical microbiology made ridiculously simple: MedMaster; 2013.

3. Cheesbrough M. District laboratory practice in tropical countries: Cambridge university press; 2006.

4. Medeiros PHQS, Lima AÂM, Guedes MM, Havt A, Bona MD, Rey LC, et al. Molecular characterization of virulence and antimicrobial resistance profile of Shigella species isolated from children with moderate to severe diarrhea in northeastern Brazil. Diagn Microbiol Infect Dis. 2017.

5. Omar MH. Prevalence of enteric Bacteria associated with diarrhea in children less than five years of age; and their sensitivity to antibiotics in Unguja Island. Zanzibar: The Open University of Tanzania; 2015.

6. Wardlaw T, Salama P, Brocklehurst C, Chopra M, Mason E. Diarrhoea: why children are still dying and what can be done. Lancet. 2010;375(9718):8702.

7. Mengistie $B$, Berhane $Y$, Worku A. Prevalence of diarrhea and associated risk factors among children under-five years of age in eastern Ethiopia: a crosssectional study. Open Journal of Preventive Medicine. 2013;3(07):446.

8. Mzungu I, Inabo HI, Olonitola SO, Aminu M. Antibiotic susceptibilities of Salmonella species prevalent among children of 0-5 years with diarrhea in Katsina state, Nigeria. Archives of Medical and Biomedical Research. 2016; 3(1):39-51.

9. Lamboro T, Ketema T, Bacha K. Prevalence and antimicrobial resistance in Salmonella and Shigella species isolated from outpatients, Jimma University specialized hospital, Southwest Ethiopia. Canadian Journal of Infectious Diseases and Medical Microbiology. 2016;2016.

10. Debas G, Kibret M, Biadglegne F, Abera B. Prevalence and antimicrobial susceptibility patterns of shigella species at Felege Hiwot referral hospital, Northwest Ethiopia. Ethiop Med J. 2011;49(3):249-56.

11. Mekonnen $\mathrm{H}$, Kebede A, Menkir S. Isolation rate and drug resistance patterns of Shigella species among diarrheal patients attending at Hiwot Fana hospital, Harar, Ethiopia. Ethiopian Journal of Science and Technology. 2014;7(1):15-25.

12. Central Statistical Agency - CSA/Ethiopia, ICF. Ethiopia Demographic and Health Sruvey 2016. Addis Ababa, Ethiopia: CSA and ICF; 2017.

13. Mache A. Antibiotic resistance and sero-groups of Shigella among paediatric out-patients in southern Ethiopia. East Afr Med J. 2001;78(6):2969.

14. Perilla MJ, Bopp C, Elliott J, Facklam R, Popovic T, Wells J, et al. Manual for the laboratory identification and antimicrobial susceptibility testing of bacterial pathogens of public health importance in the developing world: Haemophilus influenzae, Neisseria meningitidis, Streptococcus pneumoniae, Neisseria gonorrhoea, Salmonella serotype Typhi, Shigella, and Vibrio cholerae. 2003.

15. Patel JB. Performance standards for antimicrobial susceptibility testing: Clinical and Laboratory Standards Institute; 2017.

16. Nunes MR, Magalhães PP, Penna FJ, Nunes JM, Mendes EN. Diarrhea associated with Shigella in children and susceptibility to antimicrobials. J Pediatr. 2012;88(2):125-8.

17. Fletcher S, Sibbritt D, Stark D, Harkness J, Rawlinson W, Andresen D, et al. Descriptive epidemiology of infectious gastrointestinal illnesses in Sydney, Australia, 2007-2010. Western Pacific surveillance and response journal: WPSAR. 2015;6(4):7.

18. Urvashi SS, Dutta R. Antimicrobial resistance pattern of Shigella species over five years at a tertiary-care teaching hospital in North India. J Health Popul Nutr. 2011;29(3):292

19. Ansari S, Sherchand J, Parajuli K, Mishra S, Dahal R, Shrestha S, et al. Bacterial etiology of acute diarrhea in children under five years of age. J Nepal Health Res Counc. 2012;10(22):218-23.

20. Altayyar IA, Abdalla AM. Antibiotic susceptibility patterns and Sero-grouping of Salmonella isolated from clinical specimens in Eastern Province, Saudi Arabia. Emer Life Sci Res. 2015;1(2):8-12.

21. Hamze M, Osman M, Mallat $H$, Achkar M. Antibiotic susceptibility of Salmonella spp., Shigella spp. and enteropathogenic Escherichia coli strains isolated from diarrheic children in Tripoli, North Lebanon. The International Arabic Journal of Antimicrobial Agents. 2016;6(2).

22. Mahmoudi S, Pourakbari B, Moradzadeh M, Eshaghi H, Ramezani A, Ashtiani MTH, et al. Prevalence and antimicrobial susceptibility of Salmonella and Shigella spp. among children with gastroenteritis in an Iranian referral hospital. Microb Pathog. 2017;109:45-8. 
23. Getamesay M, Getenet B, Ahmed Z. Prevalence of shigella, salmonella and cmpylobacter species and their susceptibility patters among under five children with diarrhea in hawassa town, South Ethiopia. Ethiopian Journal of Health Sciences. 2014;24(2):101-8.

24. Durumları AD. Prevalence of Salmonella and Shigella spp. and antibiotic resistance status in acute childhood gastroenteritis; 2015.

25. Yu J, Jing H, Lai S, Xu W, Li M, Wu J, et al. Etiology of diarrhea among children under the age five in China: results from a five-year surveillance. J Infect. 2015;71(1):19-27.

26. Amukoshi M, Maposa I, Moyo SR, Mukesi M. Etiological agents isolated from stool samples of children under the age of five years in Windhoek, Namibia. Edorium Journal of Microbiology. 2017;3:1-9.

27. Mamuye Y, Metaferia G, Birhanu A, Desta K, Fantaw S. Isolation and antibiotic susceptibility patterns of Shigella and Salmonella among under 5 children with acute diarrhoea: a cross-sectional study at selected public health facilities in Addis Ababa, Ethiopia. Clinical Microbiology: Open Access. 2015.

28. Kahsay AG, Teklemariam Z. Prevalence of Shigella among diarrheic children under-5 years of age attending at Mekelle health center, North Ethiopia. BMC research notes. 2015;8(1):788.

29. Sánchez-Vargas FM, Abu-El-Haija MA, Gómez-Duarte OG. Salmonella infections: an update on epidemiology, management, and prevention. Travel Med Infect Dis. 2011:9(6):263-77.

30. YEMANE G, MULAW G, GAIM T. Prevalence and antimicrobial susceptibility of Salmonella species in diarrheal children under five-years of age in Bahir Dar town, Ethiopia. Int J Int sci Inn Tech Sec A. 2014;3(2):12-7.

31. Reda AA, Seyoum B, Yimam J, Fiseha S, Jean-Michel V. Antibiotic susceptibility patterns of Salmonella and Shigella isolates in Harar, eastern Ethiopia. Journal of Infectious Diseases and Immunity. 2011;3(8):134-9.

32. Yang H, Chen G, Zhu Y, Liu Y, Cheng J, Hu L, et al. Surveillance of antimicrobial susceptibility patterns among Shigella species isolated in China during the 7-year period of 2005-2011. Annals of laboratory medicine. 2013;33(2):111-5

Ready to submit your research? Choose BMC and benefit from:

- fast, convenient online submission

- thorough peer review by experienced researchers in your field

- rapid publication on acceptance

- support for research data, including large and complex data types

- gold Open Access which fosters wider collaboration and increased citations

- maximum visibility for your research: over $100 \mathrm{M}$ website views per year

At $\mathrm{BMC}$, research is always in progress.

Learn more biomedcentral.com/submissions 